\title{
The Impact of Gestational Length on Human Milk Selenium Concentration and Glutathione Peroxidase Activity ${ }^{1}$
}

\author{
L. ELLIS, M. F. PICCIANO, A. M. SMITH, M. HAMOSH, AND N. R. MEHTA
}

School of Human Resources and Family Studies and Division of Nutritional Sciences, University of Illinois, Urbana, Illinois 61801 [L.E., M.F.P., A.M.S.]; and Department of Pediatrics, Georgetown University Medical School, Washington, DC 20007 [M.H., N.R.M.]

\begin{abstract}
Longitudinal changes in selenium (Se) and protein concentrations and glutathione peroxidase (GSHPx) activity of milk collected from healthy mothers of term $(n=12)$, preterm $(n=10)$, and very preterm $(n=12)$ infants were assessed. All infants were size appropriate for gestational age. Milk samples representative of colostrum (d 3), transitional (d 7 ), and mature milk (d 21 and 42) were assayed. The content of $\mathrm{Se}$ in the colostrum secreted by mothers of preterm infants was significantly greater than the Se content of milk secreted by the same mothers at $d 21$ and 42 of lactation. Mothers of term and very preterm infants, however, produced colostrum with significantly higher levels of Se than milk produced at $\mathrm{d} 7(p<$ $0.05)$, d $21(p<0.01)$, or d $42(p<0.001)$. Significant differences between the protein concentrations measured in early lactation and in late lactation were evident in all maternal groups. Protein content did not differ significantly among groups at anytime during lactation. An age-related difference was detected in milk GSH-Px activities of mature milk (d 21). Mature milk produced by mothers of very preterm infants on $\mathbf{2} 2$ of lactation contained significantly greater enzyme activity $(p<0.05)$ than milk produced by mothers of term infants at the same stage of lactation. Activity of GSH-Px in milk from mothers of very preterm and preterm infants paralleled previously noted changes in long-chain polyunsaturated fatty acid content in human milk with the progression of lactation. Although the function of GSH-Px in milk is unknown, results from this study suggest a possible role in the protection of milk lipids from oxidative damage. (Pediatr Res 27:32-35, 1990)
\end{abstract}

\section{Abbreviations}

Se, selenium

GSH-Px, glutathione peroxidase

$T$, term

PT, preterm

VPT, very preterm

LCP, long-chain polyunsaturated fatty acids

Received April 11, 1989; accepted September 5, 1989.

Correspondence Dr. M. F. Picciano, The Pennsylvania State University, S-126B Henderson Building South, University Park, PA 16802.

Supported in part by National Institutes of Health Grants 18689 and 20833 and the Illinois Agricultural Experiment Station.

${ }^{1}$ Presented in part at the III International Congress of Nutrition in Brighton, England.
The nutritional essentiality of Se was first recognized by Schwartz and Foltz (1). Further research identified se as an integral part of the enzyme, GSH-Px (2), which functions to protect cells from oxidative damage by hydrogen or lipid peroxides. Although the role of Se has been studied in various human and animal populations (3-8), its importance in infant nutrition is largely unexplored.

During the first months of life, the infant survives on milk as the principal source of nutrition. Nutrient requirements for term infants are often based on the composition of human milk and the average volume of milk consumed within a 24 -h period (8). Recommendations for nutrient intakes of PT infants are established on the perspective of human milk as the ideal food source $(9,10)$. However, research of the nutritional requirements of preterm infants has indicated significant differences in the composition of PT and T human milk over the course of lactation (9-14).

Although the presence of both Se and GSH-Px in human milk from mothers of term infants has been identified and quantified at various stages of lactation (15-18), little is known regarding the presence of these species in milk from mothers of PT infants. Thus, the objective of this study was to determine profiles of the content of Se and activity of GSH-Px in milk of preterm infants and to compare values with those obtained from mothers delivering $\mathrm{T}$ infants. In addition, we sought to determine whether compositional changes of Se or GSH-Px in milk from mothers of PT infants were influenced by varying lengths of gestation and lactation.

\section{MATERIALS AND METHODS}

Milk samples were collected from 34 healthy mothers delivering infants of size appropriate for gestational age. Subjects were divided into three experimental groups based on the duration of gestation. VPT $(n=12)$ were defined as gestational age of 26$30 \mathrm{wk}, \mathrm{PT}(n=10)$ as $31-37 \mathrm{wk}$, and T $(n=12)$ as $38-40 \mathrm{wk}$ Gestational age of the infant was assessed based on maternal report and confirmation by prenatal and postnatal examination $(19,20)$. The use of human subjects in this study was reviewed and approved by the Institutional Review Boards of Georgetown University and the University of Illinois.

All samples were collected in the Washington, DC area, stored at $-20^{\circ} \mathrm{C}$, and shipped frozen on dry ice to the University of Illinois for analysis. The entire content of one breast was expressed with an electric breast pump (Egnell Inc., Cary, IL) between 0900 and $1000 \mathrm{~h}$ on the day of sampling. Longitudinal collection of samples from each mother occurred on postpartum d 1-4 (colostrum), 7 (transitional milk), and 21 and 42 (mature 
milk). Colostrum samples are designated as d-3 samples in this report.

Se concentration was measured by the method of McCarty et al. (21) using a gas chromatograph (Hewlett-Packard model 5710A, Avondale, PA) equipped with an electron capture detector (model 5709A) and automatic sample injector (model 7671A). Bovine nonfat milk powder (National Bureau of Standards reference material no. 1549, Gaithersburg, MD) served as the reference standard for assessing accuracy and reproducibility of the Se measurement. Mean Se concentration determined from analysis of this reference standard was $0.12 \pm 0.01 \mu \mathrm{g} / \mathrm{g}$ compared to the certified value of $0.11 \pm 0.01 \mu \mathrm{g} / \mathrm{g}$.

GSH-Px activity was measured using a modification of the coupled assay of Paglia and Valentine (22). Upon thawing at room temperature, samples were centrifuged $(10000 \times g)$, defatted via vacuum suction, and held on ice until assayed. The reaction mixture contained $50 \mathrm{mM}$ potassium phosphate buffer, pH 7.0, 1 mM EDTA, $1 \mathrm{mM} \mathrm{NaN3}, 0.2 \mathrm{mM}$ NADPH, $1 \mathrm{U} / \mathrm{mL}$ glutathione, $0.1 \mathrm{mM} \mathrm{H}_{2} \mathrm{O}_{2}$, and $0.1-0.2 \mathrm{~mL}$ unknown sample in a total volume of $1 \mathrm{~mL}$. One unit of GSH-Px activity is defined as $1 \mu \mathrm{mol} \mathrm{NADPH}$ oxidized per min at $25^{\circ} \mathrm{C}$. Blanks were prepared from heat denatured samples. Total protein concentration was determined spectrophotometrically at $562 \mathrm{~nm}$ using the Pierce BCA colorimetric assay. Bovine serum albumin served as the reference standard for this assay.

Repeated measures analysis of variance statistics, least significant difference test, and correlational statistics (23) were used in data evaluation. The level of probability defining statistical significance was $5 \%$.

\section{RESULTS}

Mean values of milk Se are provided in Table 1. Although Se values of milk samples varied greatly between individual subjects, milk Se was greatest in colostrum of all groups. Levels of Se remained relatively stable in milk from the VPT and PT groups after d 3 of lactation. Results of correlational analyses showed that the rate of change in milk Se with time was greater for the $\Upsilon$ group $(r=-0.61)$ than for the PT group $(r=-0.38)$ or for the VPT group ( $r=-0.33$ ). In both VPT and T groups, significant effects between day of lactation and milk Se content were noted. Milk from mothers of VPT infants contained significantly more Se in colostrum than in mature milk (d 21, $p<0.05$ ). Additionally, the Se content of colostrum secreted by the mothers of $\mathrm{T}$ infants differed significantly from all other time points in lactation (d 7, $p<0.05$; $21, p<0.01 ; \mathrm{d} 42, p<0.001$ ). No differences were noted in Se values among groups on any collection date.

Changes in protein concentration of human milk samples are summarized in Table 2. Significant differences in protein con-

Table 1. Se concentration in milk samples from mothers of $V P T, P T$, and $T$ infants at various stages of lactation $($ mean $\pm S E M)$

\begin{tabular}{ccccc}
\hline & \multicolumn{4}{c}{ Day of lactation } \\
\cline { 2 - 5 } Group*† & 3 & 7 & 21 & 42 \\
\hline & \multicolumn{5}{c}{$(\mu$ mol/L) } \\
VPT & $0.41 \pm 0.04$ & $0.33 \pm 0.02$ & $0.31 \pm 0.03$ & $0.32 \pm 0.05^{\mathrm{a}}$ \\
$n=$ & 11 & 12 & 10 & 9 \\
PT & $0.40 \pm 0.07$ & $0.34 \pm 0.03$ & $0.32 \pm 0.02$ & $0.29 \pm 0.04^{\mathrm{ab}}$ \\
$n=$ & 5 & 10 & 9 & 8 \\
$\mathrm{~T}$ & $0.41 \pm 0.04$ & $0.33 \pm 0.02$ & $0.30 \pm 0.02$ & $0.27 \pm 0.02^{\mathrm{b}}$ \\
$n=$ & 10 & 9 & 9 & 10 \\
\hline
\end{tabular}

$*$ Within each group, significant effects of day of lactation were noted. VPT: $\mathrm{d} 3>\mathrm{d} 7,21,42 ; p<0.05-0.01$. PT: $\mathrm{d} 3>\mathrm{d} 21,42 ; p<0.05$. T: d $3>$ d 7, 21, 42; $p<0.05-0.001$.

$\dagger$ At d 42 of lactation, means with unlike superscripts differ at $p<$ 0.05 .
Table 2. Total protein content in milk samples from mothers of $V P T, P T$, and $T$ infants at various stages of lactation (mean $\pm S E M)$

\begin{tabular}{lcccc}
\hline & \multicolumn{4}{c}{ Day of lactation } \\
\cline { 2 - 5 } Group* & 3 & 7 & 21 & 42 \\
\hline & \multicolumn{4}{c}{$(g / L)$} \\
VPT & $23.2 \pm 1.5^{\mathrm{ab}}$ & $21.3 \pm 1.3$ & $17.6 \pm 1.1$ & $17.2 \pm 1.5$ \\
$n=$ & 9 & 12 & 9 & 8 \\
PT & $23.0 \pm 3.8^{\mathrm{a}}$ & $22.5 \pm 3.5$ & $17.7 \pm 0.8$ & $16.6 \pm 1.6$ \\
$n=$ & 7 & 10 & 9 & 9 \\
$\mathrm{~T}$ & $21.0 \pm 1.6^{\mathrm{b}}$ & $19.5 \pm 1.5$ & $17.6 \pm 1.6$ & $16.5 \pm 1.0$ \\
$n=$ & 9 & 10 & 9 & 11 \\
\hline
\end{tabular}

* Within each group, significant effects of day of lactation were noted. VPT: $\mathrm{d} 3>21,42 ; p<0.01 ; \mathrm{d} 7>21,42 ; p<0.05$. PT: $\mathrm{d} 3>21>42$; $p<0.05 ; \mathrm{d} 7>21 ; p<0.05$. T: d $3>\mathrm{d} 42 ; p<0.05$.

Table 3. Glutathione peroxidase activity in milk samples from mothers of VPT, PT, and T infants at various stages of lactation (mean $\pm S E M)$

\begin{tabular}{lcccc}
\hline & \multicolumn{4}{c}{ Day of lactation } \\
\cline { 2 - 5 } Group & 3 & 7 & 21 & 42 \\
\hline VPT & $29.7 \pm 12$ & $36.8 \pm 5.0$ & $39.2 \pm 5.0^{\mathrm{a}}$ & $35.4 \pm 3.0$ \\
$n=$ & 5 & 10 & 10 & 7 \\
PT & $39.7 \pm 16$ & $28.8 \pm 8.4$ & $30.1 \pm 5.2^{\mathrm{ab}}$ & $33.2 \pm 8.7$ \\
$n=$ & 4 & 6 & 8 & 6 \\
T & $28.2 \pm 4.1$ & $28.2 \pm 4.4$ & $22.9 \pm 2.7^{\mathrm{b}}$ & $29.5 \pm 5.5$ \\
$n=$ & 9 & 6 & 9 & 10 \\
\hline
\end{tabular}

* At d 21 of lactation, means with unlike superscript differ at $p<0.01$.

centration with the progression of lactation were noted for all groups.

The values for GSH-Px in the milk produced by the three groups of women are shown in Table 3. Activity of GSH-Px remained relatively stable throughout lactation in milk secreted by mothers of $T$ infants, whereas enzyme activities measured in the VPT and PT samples appeared to stabilize after d 3 of lactation. Despite the apparent differences between GSH-Px activity measured in the colostrum and in the transitional milk produced by mothers of VPT and PT infants, no effect of the day of lactation was significant in VPT, PT, or T groups. Agerelated effects, however, were noted in mature milk (d 21). Mature milk produced on $\mathrm{d} 21$ by mothers of VPT infants possessed significantly more activity of GSH-Px $(p<0.05)$ than the milk produced by mothers of $T$ infants.

\section{DISCUSSION}

The results of this study show parallel compositional changes in the Se content of milk from mothers of VPT, PT, and T infants throughout the first $6 \mathrm{wk}$ of lactation. The requirement of Se by the VPT and PT population is unknown and the clinical implications of Se supplementation in the VPT and PT infant remain to be demonstrated. Yet, despite decreased nutrient stores and increased nutrient requirements imposed by catch-up growth and/or existing illness commonly associated with premature birth, premature infants often receive total parenteral nutrition devoid of Se or formula containing only $25 \%$ of the Se (17) provided by the same volume of milk from mothers of VPT and PT infants reported in this study.

The activity of GSH-Px throughout lactation in milk from mothers of VPT and PT infants has not been previously reported. Changes in GSH-Px activity from colostrum to transitional milk of mothers of VPT and PT infants were different than the pattern of stable activity of milk GSH-Px apparent in milk of mothers of $T$ infants. Differences in enzyme activities among VPT, PT, 
and T groups at $\mathrm{d} 21$ of lactation may perhaps be physiologically explained by maturation of the mammary gland. Although the activity of GSH-Px in milk produced by mothers of VPT infants at $\mathrm{d} 7$ appears elevated as compared with the enzyme activity found in milk of the PT and T groups by $\mathrm{d} 21$, these apparent differences persist and become statistically significant.

The presence of GSH-Px in milk of many species [i.e. human, cow, goat (24), and rat (25)] suggests a functional significance of the enzyme to events occurring in the mammary gland, and/or to the postpartum development of the neonate. In other tissues GSH-Px functions to protect lipids from oxidative damage (26). High levels of LCP are associated with the membrane of the human milk fat globule. Comparison of these data with profiles of lipid expressed in human milk suggests a possible association between the activity of GSH-Px and the long-chain polyunsaturated lipid content of human milk. A positive correlation between the concentration of milk LCP and the degree of prematurity of the infant has been reported (14). A similar trend was noted in the GSH-Px activity profiles of VPT, PT, and T groups reported in this study. The activity of GSH-Px at all stages of lactation was greatest in milk from mothers of PT and VPT infants and lowest in milk from mothers of $T$ infants. Although lipid composition data are not available for the milk samples of this study, the lipid profiles reported by Bitman et al. (14) are derived from a similar population in the Washington, DC area using identical sample collection methods and processing techniques.

The elevation in milk GSH-Px activity at a similar time in which the concentration of LCP is highest in VPT and PT milk suggests that the enzyme may have an associated or complementary role with fatty acids in milk secretion and/or the nutrition of the infant. Thus, the pattern of milk GSH-Px activity may be a direct result of the quantity or type of lipid present in human milk at specific points of lactation. In further support of this association, vegetarian women who delivered term infants secreted milk with a greater content of linoleic acid and activity of GSH-Px than did nonvegetarian women (27). A major component of the bovine milk fat globule membrane is the enzyme, xanthine oxidase, which is believed to function in milk fat secretion by peroxidizing membrane-associated lipids, thus affecting the fluidity of the milk fat globule (28). The human milk fat globule membrane has a very low level of xanthine oxidase but is very fluid due to the characteristically high LCP content. It is possible that GSH-Px may play an antioxidant role in protection of the structure of the human milk fat globule membrane.

The implications of this study are 2-fold. First, although levels of Se are very similar between milk secreted by mothers of VPT, $\mathrm{PT}$, and T infants throughout lactation, the discrepancy between the levels of Se provided by current nutrition approaches and that provided by human milk is substantial. VPT and PT infants fed parenterally receive no Se supplementation, whereas pediatric enteral formulas contain only one-fourth of the Se per unit volume as compared to human milk.

Evidence of Se deficiency in the preterm population has recently been reported (29). Baseline levels of plasma Se and GSHPx activity were significantly lower in low birth wt infants than in full-term infants. Furthermore, marked declines in the levels of plasma Se accompanied by a reduction in plasma GSH-Px activity were observed in low birth wt infants maintained on parenteral formula. Changes in plasma Se levels of healthy, fullterm infants fed either human milk or commercial formula have been examined $(17,30)$. Plasma Se values in infants fed human milk are significantly higher than those fed commercial formula and in some formula-fed infants low plasma Se values are associated with reduced plasma activity of GSH-Px. Although the clinical significance of these findings is unknown, it is apparent that gestational length and method of feeding directly impact on infant Se status.

An association between low levels of blood Se and exacerba- tions of bronchopulmonary dysplasia has been proposed in an infant supported on prolonged parenteral nutrition (31). The late gestational maturation of the antioxidant enzyme system is a normal aspect of fetal lung development in experimental animals (32-35). Animal data show that increases in antioxidant enzyme response of the neonate parallel increases in levels of environmental oxygen (33). GSH-Px is an integral component of the antioxidant defense of lung tissue. Although measurable amounts of the non-Se-dependent forms of the peroxidase enzyme exist in other tissues, lung tissue contains principally the Se-dependent form of GSH-Px (36). Failure to provide adequate levels of $\mathrm{Se}$ during early life may stunt the maturation of the antioxidant enzyme system and may ultimately contribute to prolonged complications associated with bronchopulmonary dysplasia.

GSH-Px activity is present in the milk of mothers of VPT and PT infants. Comparison of enzyme profiles reported in this study with data on LCP in human milk reported elsewhere point to a possible physiologic role of the enzyme in human milk. Further studies are needed to examine this association.

\section{REFERENCES}

1. Schwartz K, Foltz CM 1957 Selenium as an integral part of factor 3 against dietary necrotic liver degeneration. J Am Chem Soc 79:3292-3293

2. Mills GC 1959 The purification and properties of glutathione peroxidase of erythrocytes. J Biol Chem 234:502-506

3. Rose J 1983 Trace Elements in Health: A Review of Current Issues. Butterworth \& Co Ltd, Boston

4. Xiaoshu C 1980 Studies on the relations of selenium and Keshan disease. Biol Trace Elem Res 2:91-107

5. Johnson RA, Baker SS, Fallon JT, Maynard EP, Rusken JN, Wen Z 1981 An occidental case of cardiomyopathy and selenium deficiency. N Engl J Med 304:1210-1212

6. Collipp PJ, Chen SY 1981 Cardiomyopathy aned selenium deficiency in a two year old girl. N Engl J Med 304:1304-1305

7. Baker SS, Lerman RH, Krey SH 1983 Selenium deficiency with total parenteral nutrition: reversal of biochemical and functional abnormalities by selenium supplementation: a case report. Am J Clin Nutr 38:769-774

8. Food and Nutrition Board/National Academy of Sciences 1980 Recommended Dietary Allowances, 9th ed. National Academy of Sciences, Washington, $\mathrm{DC}$

9. Anderson GH, Bryan MH 1982 Is the premature infant's own mother's milk best? J Pediatr Gastroenterol Nutr 1:157-159

10. Hartmann PE, Prosser CG 1984 Physiological basis of longitudinal changes in human milk yield and composition. Fed Proc 43:2448-2453

11. Mendelson RA, Bryan MH, Anderson GH 1983 Trace mineral balances in preterm and infants fed their own mother's milk. J Pediatr Gastroenterol Nutr 2:256-261

12. Butte NF, Garza C, Johnson CA, Smith EO, Nichols BL 1984 Longitudinal changes in milk composition of mothers delivering preterm and term infants. Early Hum Dev 9:153-162

13. Anderson GH 1984 The effect of prematurity on milk composition and its physiological basis. Fed Proc 43:2438-2442

14. Bitman J, Wood L, Hamosh M, Hamosh P, Mehta NR 1983 Comparison of the lipid composition of breast milk from mothers of term and preterm infants. Am J Clin Nutr 38:300-312

15. Shearer TR, Hadjimarkos DM 1975 Geographical distribution of selenium in human milk. Arch Environ Health 30:230-233

16. Higashi A, Tamari $\mathrm{H}$, Kuroki Y, Matsuda I 1983 Longitudinal changes in the selenium content of breast milk. Acta Paediatr' Scand 72:433-436

17. Smith AM, Picciano MF, Milner JA 1982 Selenium intakes and status of human milk and formula fed infants. Am J Clin Nutr 35:521-526

18. Mannan S, Picciano MF 1987 Influence of maternal selenium status on human milk selenium concentration and glutathione peroxidase activity. Am $\mathbf{J}$ Clin Nutr 46:95-100

19. Usher R, McLean F 1969 Intrauterine growth of live-born Caucasian infants at sea level. Standards obtained from measurements in 7 dimensions of infants born between 25 and 44 weeks gestation. J Pediatr 10:341-344

20. Dubowitz MS, Dubowitz V, Goldberg C 1970 Clinical assessment of gestational age in the newborn infant. J Pediatr 77:1-10

21. McCarthy TP, Brodie JA, Beville RF 1981 Improved method for selenium determination in biological samples by gas chromatography. $J$ Chromatogr 225:9-16

22. Paglia DE, Valentine WN 1967 Studies on the quantitative and qualitative characterization of erythrocyte glutathione peroxidase. J Lab Clin Med 70:159-169

23. Nie NH, Hull CH, Jenkins JG, Steinbrenner K, Bent DH 1975 SPSS: Statistical Package for the Social Sciences, 2nd ed. McGraw-Hill, New York

24. Debski B, Picciano MF, Milner JA 1987 Selenium content and distribution of human, cow, and goat milk. J Nutr 117:1091-1097

25. Smith AM, Picciano MF 1987 Relative bioavailability of selenocompounds in 
the lactating rat. J Nutr 117:725-731

26. Combs G, Combs SB 1984 The nutritional biochemistry of selenium. Ann Rev Nutr 4:257-280

27. Debski B, Picciano MF, Milner J 1989 Selenium content and GSH-Px of milk from vegetarian and non-vegetarian women? J Nutr 119:215-220

28. Mepham TB 1983 Biochemistry of Lactation. Elsevier Science Publishing Co, New York

29. Lockitch G, Jacobson B, Quigley G, Dison P, Pendray M 1989 Selenium deficiency in low birth weight neonates: an unrecognized problem. $J$ Pediatr 114:865-870

30. Smith AM, Picciano MF, Milner JA, Hatch TF 1988 Influence of feeding regimens on selenium concentrations on glutathione peroxidase activities in plasma and erythrocytes of infants. J Trace Elem Exp Med 1:209-216
31. Amin S, Chen SY, Collip PJ, Castro-Magan M, Maddiah JVT, Klein SW 1981 Selenium in premature infants. Nutr Metab 24:331-340

32. Frank L Groseclose EE 1982 Oxygen toxicity in newborn rats: the adverse effects of undernutrition. J Appl Physiol 53:1248-1255

33. Frank L 1985 Effects of oxygen on the newborn. Fed Proc 44:2328-2334

34. Frank L, Groseclose EE 1984 Preparation for birth into an $\mathrm{O}_{2}$ rich environment: the antioxidant enzymes in the developing rabbit lung. Pediatr Res 18:240-244

35. Frank L, Sosenko I 1987 Development of lung antioxidant enzyme system in late gestation: possible implications for the prematurely born infant. J Pediatr 110:9-14

36. Lawrence RA, Burke RF 1978 Species, tissue, and subcellular distribution of non-Se-dependent glutathione peroxidase activity. J Nutr 108:211-215

\section{Announcements}

\section{Call for Abstracts}

The Society for Behavioral Pediatrics will conduct its 8th Annual Scientific Meeting on September 16-17, 1990 at the Westin Hotel in Denver, CO. We invite you to submit abstracts of research papers for consideration for presentation at the scientific sessions. ABSTRACTS MUST BE RECEIVED BY MARCH 1, 1990. For further information and abstract forms, please contact: Ms. Noreen Spota, SBP Business Administrator, 241 East Gravers Lane, Philadelphia, PA 19118, (215) 248-9168.

\section{Special Program in Nutrition for a Healthy Heart Developed for Grade School Children and Their Parents}

The J. David Gladstone Foundation of the University of California, San Francisco, has developed a heart healthy nutrition education curriculum for third grade students and their parents. This curriculum, called the Special Program in Nutrition (SPIN), consists of two manuals and a cookbook collection of low fat, low cholesterol recipes. The manuals contain an in-service program for teachers, 27 lessons for third grade students, seven lessons for fourth grade students, and a parent's program with ten planned meetings.

The cost of the complete set is $\$ 35.00$; the two-volume curriculum and the cookbook may be purchased separately for $\$ 30.00$ and $\$ 10.00$, respectively. Add $6.5 \%$ California sales tax where applicable. For further information contact: The Gladstone Foundation Laboratories, 2550 23rd Street, P.O. Box 40608, San Francisco, CA $94140,(415)$ 826-7500.

\section{Third Congress on Trace Elements in Medicine and Biology}

The French Society for Study and Research on Essential Trace Elements will hold its Third Congress on Trace Elements in Medicine and Biology at Les Deux Alpes, France, January 15-18, 1991. For additional information contract: Arlette Alcaraz, Laboratoire de Biochimie C-CHRU de Grenoble, BP 217 X, 38043 Grenoble CEDEX. Telephone: 76.42.81.21, extension 4465 .

\section{ANNUAL MEETINGS}

The American Pediatric Society, The Society for Pediatric Research and The Ambulatory Pediatric Association will meet May 7-1 1, 1990; Anaheim Hilton \& Towers and Convention Center, Anaheim, CA.

Contact: APS or SPR: Association Headquarters, 2650 Yale Blvd., S.E., Suite 104, Albuquerque, NM 87106, (505) 764-9099 or 0068. APA: Ambulatory Pediatric Association, 6728 Old McLean Village, McLean, VA 22101, (703) 556-9222.

\section{FASEB Summer Conference on Physiology and Pathophysiology of the Splanchnic Circulation}

The FASEB Summer Research Conference, "Physiology andd Pathophysiology of the Splanchnic Circulation," will be held at Copper Mountain, CO on July 22-27, 1990. For further information contact The Federation of American Societies for Experimental Biology, Splanchnic Circulation Conference, 9650 Rockville Pike, Bethesda, MD 20814. 